NASZA DERMATOLOGIA Online OUR DERMATOLOGY Online

Source of Support: Nil

Competing Interests: None

\section{ERUPTIVE PIGMENTED PATCHES IN A PATIENT WITH HIV INFECTION UNDER HAART}

\author{
Taeko Nakamura-Wakatsuki, Toshiyuki Yamamoto
}

Department of Dermatology, Fukushima Medical University, Hikarigaoka 1, Fukushima 960-1295, Japan

Corresponding author: Taeko Nakamura-Wakatsuki M.D., Ph.D. tnw0203@gmail.com

\begin{abstract}
Introduction: Highly active antiretroviral therapy (HAART) is a standard treatment for HIV-infected patients. It has been reported that emtricitabine rarely induces skin pigmentation in the palms and soles. We herein report a Japanese case which presented a number of small pigmented patches on the acral sites.

Main observation: A 58-year-old Japanese man complained about multiple brownish skin pigmentations on his both palms and soles after 2 months of HAART therapy. Dermatoscopic observation showed a homogeneous light brown pattern. In spite of continuance of HAART, these lesions spontaneously regressed within 11 months.

Conclusion: We should know about the eruptive pigmented patches as an adverse effect under HAART with HIV infected patients.
\end{abstract}

Key words: HIV; HAART; emtricitabine; skin pigmentation; adverse effect

\section{Introduction}

Highly active antiretroviral therapy (HAART) is a standard treatment for HIV-infected patients. It has been reported that emtricitabine rarely induces skin pigmentation in the palms and soles. We herein report a Japanese case which presented a number of small pigmented patches on the acral sites.

\section{Case Report}

A 58-year-old Japanese man complained of multiple skin pigmentations on his palms and soles. He had been under treatment for HIV infection with HAART of emtricitabine and lopinavir/ritonavir for 2 months. A physical examination revealed a number of small light-brownish patches on his bilateral palms and soles (Fig. 1 a, b). Dermatoscopic observation showed a homogeneous light brown pattern without any network that support melanin deposition rather than melanocystic lesion (Fig. 2). Laboratory investigations revealed severe pancytopenia (WBC: 1700 cells/ $\mu$; RBC: $3.14 \times 10^{6}$ cells/ $\mu \mathrm{l}$; platelet: $8.7 \times 10^{4}$ cells $\left./ \mu \mathrm{l}\right)$. CD4 cells count was 20.4 cells $/ \mu \mathrm{l}$ in particular. A HIV-viral load was $3.4 \times 10^{6}$ copies $/ \mathrm{ml}$. He was diagnosed with emtricitabine-associated skin pigmentation. In spite of continuance of HAART, many of those pigmentations spontaneously disappeared or turned pale 11 months later.

\section{Discussion}

Skin pigmentations are sometimes seen among HIV-infected patients under treatment with HAART. There was an ethnic difference in the occurrence ratio between non-Caucasian and Caucasian (African-American: 8\%, Asian: 4\%, Hispanic: 3\% v.s. Caucasian: less than 1\%). The skin pigmentation appeared at a median 124 days (range: 7-259 days) and a median number of skin pigmentations was 6.5 (range: 1 to over 50). Generally, the outcome of the pigmentations was mild and disappeared at a median 112 days (range: 28-315). Histopathological findings of the skin pigmentation show increasing of melanin in the basal layer of epidermis similar to lentigo solaris. In the previous report, emtricitabine-associated skin pigmentation occurred $3.9 \%$ of Japanese patients [1], however, very few case reports have been seen. Of note, our case showed more than fifty pigmented macules on his palms and soles, many of which regressed spontaneously or turned pale within 11 months. Unfortunately, skin biopsies were not carried out. Interestingly, Namakoola et al [2] described that nail and oral pigmentation are associated with low CD4 count $(<200$ cells/ $\mu$ l) among HIV-infected individuals under antiretroviral therapy, which may link eruptive skin pigmentation and immunosuppression. Although the pathogenesis of skin pigmentations induced by nucleoside reverse transcriptase inhibitors is still unclear, there might be some common mechanisms which promote melanin pigmentation in the basal layer. Further studies will be necessary to determine the pathomechanisms of emtricitabine-induced eruptive pigmented lesions. 


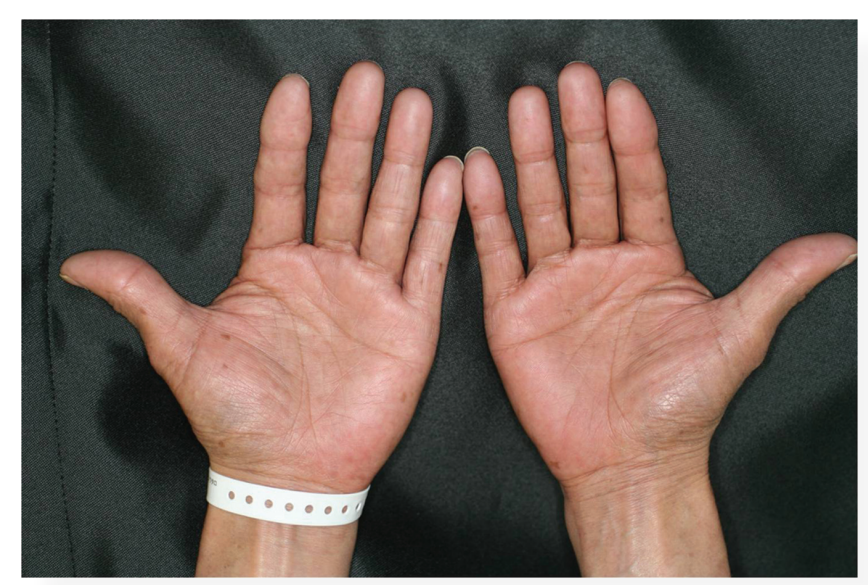

Figure 1a. Small light-brownish pigmentations on the palms.

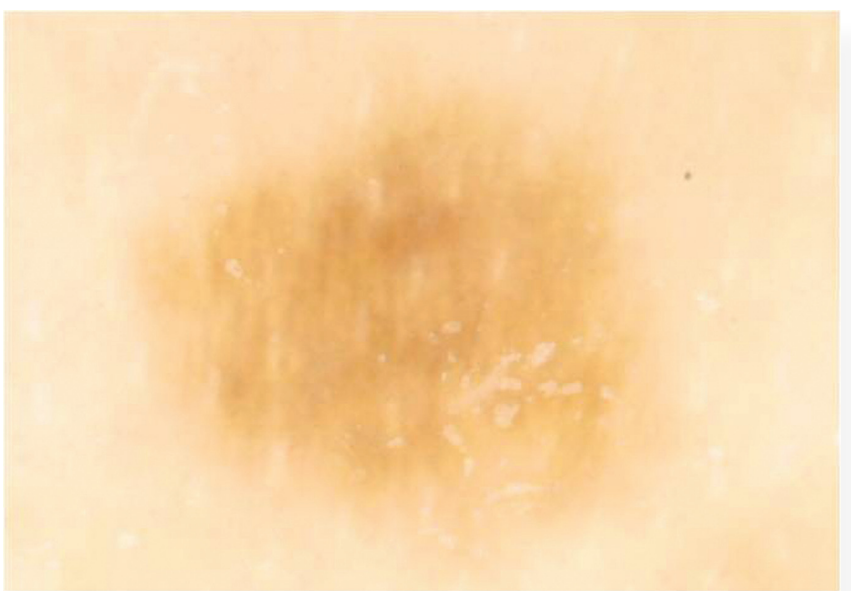

Figure 2. Dermatoscopic examination showed homogenous pattern without pigment network.

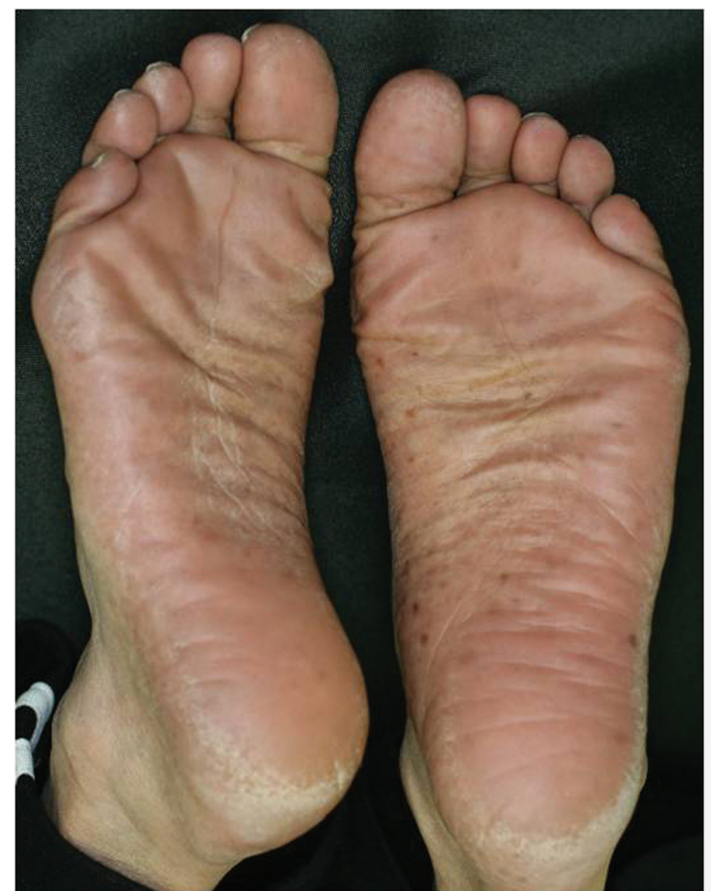

Figure 1b. Small light-brownish pigmentations on the soles.

\section{REFERENCES}

1. Shirasaka T, Tadokoro T, Yamamoto Y, Fukutake K, Kato Y, Odawara $\mathrm{T}$, et al: Investigation of emtricitabine-associated skin pigmentation and safety in HIV-1-infected Japanese patients. J Infect Chemother. 2011;17:602-8.

2. Namakoola I, Wakeham K, Ratanshi RP, Levin J, Mugagga T, Seymour C, et al: Use of nail and oral pigmentation to determine ART eligibility among HIV-infected Ugandan adults. Trop Med Int Health. 2010;15:259-62.

Copyright by Taeko Nakamura-Wakatsuki, et al. This is an open access article distributed under the terms of the Creative Commons Attribution License, which permits unrestricted use, distribution, and reproduction in any medium, provided the original author and source are credited. 